\title{
ESTUDO DA PIRÓLISE DO BAGAÇO DE MALTE PARA A OBTENÇÃO DE BIO-ÓLEO E CARVÃ̃O
}

\author{
G.C. GONÇALVES ${ }^{1}$, R. FRANZ ${ }^{1}$, P.K. NAKAMURA ${ }^{1}$, M.T. VEIT ${ }^{2}$, K.G. FIAMETTI ${ }^{1}$, \\ G.M.C. SILVA ${ }^{1}$ \\ ${ }^{1}$ Universidade Tecnológica Federal do Paraná, Campus Toledo \\ ${ }^{2}$ Universidade Estadual do Oeste do Paraná, Departamento de Engenharia Química \\ E-mail para contato: cunha@utfpr.edu.br
}

\begin{abstract}
RESUMO - O presente trabalho teve como objetivo realizar o estudo da pirólise do bagaço de malte para a obtenção do líquido pirolítico e carvão. Os ensaios de pirólise foram realizados utilizando-se diferentes taxas de aquecimento (5 $\left.30^{\circ} \mathrm{C} \cdot \mathrm{min}^{-1}\right)$ e diferentes temperaturas de pirólise $\left(300-650^{\circ} \mathrm{C}\right)$. Foram realizadas as caracterizações físico-químicas do bagaço de malte e os produtos da pirólise. Os ensaios experimentais demonstraram que a taxa de aquecimento teve pouca influência na distribuição dos produtos da pirólise. Os ensaios de pirólise com diferentes temperaturas indicaram que, na temperatura de $500^{\circ} \mathrm{C}$, foram observados rendimentos, em massa, de $42,0 \%, 30,7 \%$ e $27,8 \%$ para os líquidos, carvão e gases, respectivamente. O líquido da pirólise apresentou separação em duas fases: aquosa e orgânica. O carvão pirolisado apresentou índice de iodo de $237,21 \mathrm{mg} \mathrm{I}_{2} / \mathrm{g}$. O bagaço de malte apresentou-se como uma fonte promissora para aplicação em processos de pirólise para a obtenção de bio-óleo e carvão.
\end{abstract}

\section{INTRODUÇÃO}

As fontes de energia utilizadas para o desenvolvimento da humanidade estão direcionadas, economicamente à utilização de combustíveis fósseis. No entanto, a queima desses combustíveis causa, entre outros, emissões de gases efeito estufa, principalmente dióxido de carbono, que ocasionam grandes problemas para o meio ambiente. Para atender a crescente demanda de energia e ajudar a diminuir os problemas do impacto ambiental, as tendências mundiais estão se direcionando para a produção de energia renovável (ASADULLAH et al., 2007).

A produção de energia a partir da biomassa apresenta-se como uma alternativa promissora para a substituição dos combustíveis fósseis. Vários tipos de biomassa, como os resíduos agrícolas, industriais, florestais, entre outros, estão disponíveis em grande quantidade para a utilização na geração de energia (MOHAN et al., 2006, ASADULLAH et al., 2007, OKUTUCU, et al., 2011, JOARDDER, et al., 20112, AI, et al., 2013).

A pirólise da biomassa é um processo de termo-conversão que antecede a gaseificação, independentemente da matéria-prima empregada. O processo de pirólise divide-se em dois grandes grupos, que são classificados de acordo com a taxa de aquecimento utilizada (SÁNCHEZ; CAMPO, 2003). A pirólise lenta ou convencional e que é conhecida também como carbonização tem por objetivo maximizar o rendimento de carvão vegetal em detrimento dos produtos líquidos e gasosos. A pirólise rápida, da qual existem várias versões, é direcionada a produção de líquidos e gases (SÁNCHEZ; CAMPO, 2003). 
O produto líquido dos processos de pirólise pode ser utilizado em forma de combustível líquido, pois apresenta uma mistura de cerca de 200 tipos de compostos orgânicos de alto valor energético, que podem ser utilizados para geração de energia em motores e turbinas. Além disso, também podem ser usados como fontes de substâncias químicas puras, tais como álcool, fenol, aldeído, ácidos orgânicos, entre outros (ASADULLAH et al., 2007).

O presente artigo teve como objetivo realizar o estudo da pirólise do bagaço de malte para a obtenção do líquido pirolítico (bio-óleo) e carvão.

\section{MATERIAIS E MÉTODOS}

\subsection{Matéria-prima}

O bagaço de malte, obtido de uma indústria cervejeira da região oeste do estado do Paraná, foi seco em estufa com circulação e renovação de ar (SOLAB modelo SL. 102/125) à temperatura de $105^{\circ} \mathrm{C}$ por 12 horas, atingindo umidade inferior a $7 \%$. O material seco foi armazenado em um barril plástico, isolado de umidade e luz. O bagaço de malte seco foi caracterizado em relação aos seguintes parâmetros:

- Análise imediata: A determinação de umidade, voláteis, cinzas e carbono fixo foram realizados de acordo com a apostila de metodologia para a realização da análise imediata de biomassas vegetais da UNICAMP (2005).

- Análise granulométrica: A análise granulométrica do bagaço de malte seco foi realizada utilizando peneiras da série Mesh Tyler; 6, 9, 14 e 28, colocadas em agitador eletromagnético BERTEL, por 15 minutos, após o peneiramento as peneiras foram pesadas e foi calculada a fração acumulada em cada uma, obtendo-se a distribuição granulométrica do bagaço de malte seco.

- Análise termogravimétrica: A análise termogravimétrica do bagaço de malte foi realizada no laboratório de Universidade Estadual de Maringá, em uma balança termogravimétrica SCHIMADZU, TGA-50, com atmosfera inerte de gás nitrogênio à vazão de $20 \mathrm{~mL} / \mathrm{min}$ e taxa de aquecimento de $10^{\circ} \mathrm{C} / \mathrm{min}$. Foi utilizada uma amostra de $6,659 \mathrm{mg}$ de bagaço de malte, conduzida entre as temperaturas de $25^{\circ} \mathrm{C}$ e $1000^{\circ} \mathrm{C}$.

- Massa específica e aparente: A massa específica aparente do bagaço de malte foi calculado a partir do volume ocupado pela biomassa em uma proveta de $250 \mathrm{~mL}$.

\subsection{Módulo de pirólise}

Para a realização dos experimentos de pirólise do bagaço de malte foi utilizada uma unidade experimental baseada nos estudos de Asadullah et al. (2007) sobre a pirólise do bagaço de cana-de-açúcar. A unidade experimental foi constituída de um forno mufla (Jung modelo 0212) com controle de temperatura, um reator confeccionado em aço inox com dimensões de $75 \mathrm{~mm}$ de diâmetro e $300 \mathrm{~mm}$ de altura e um sistema de injeção e controle de fluxo de $\mathrm{N}_{2}$ composto de cilindros de gases, válvulas reguladoras de pressão e fluxômetro. Esse reator também possui poço de termopar localizado na tampa para efetuar o controle da temperatura do processo. Para o resfriamento e coleta dos gases condensáveis (bio-óleo) foram utilizados frascos kitassatos e um condensador resfriado com água corrente a temperatura ambiente. 


\subsection{Procedimentos experimentais}

Os experimentos da pirólise do bagaço de malte foram realizados adicionando-se cerca de $85 \mathrm{~g}$ de bagaço de malte seco ao reator de pirólise com fluxo de gás $\mathrm{N}_{2}$ a uma taxa de aproximadamente $200 \mathrm{ml} / \mathrm{min}$.

Os experimentos foram conduzidos com diferentes taxas de aquecimentos e temperaturas de pirólise. Foram realizadas 4 bateladas de pirólise para observar os rendimentos dos produtos em função das diferentes taxas de aquecimento $(5,10,20$ e $30^{\circ} \mathrm{C} / \mathrm{min}$ ) até atingir a temperatura de $650^{\circ} \mathrm{C}$ permanecendo nessa temperatura por 30 minutos. Para o estudo com diferentes temperaturas foram realizados 8 bateladas de pirólise mantendo-se a taxa de aquecimento de $20^{\circ} \mathrm{C} /$ minuto até atingir a temperatura de pirólise, nas temperaturas de $300,350,400,450,500,550,600$ e $650^{\circ} \mathrm{C}$, permanecendo nessa temperatura por 30 minutos. Os produtos voláteis produzidos foram condensados e recolhidos em dois frascos Kitassatos e foram denominados de líquido de pirólise. Os gases não condensáveis foram passados por lavagem em água e descartados para a atmosfera. Após o término da pirólise o reator foi retirado do forno e resfriado, ao fluxo de nitrogênio até chegar à temperatura inferior a $100^{\circ} \mathrm{C}$. A massa do resíduo sólido, denominado de carvão, foi determinada em uma balança. Os percentuais de rendimento em massa do carvão, líquido e gases da pirólise foram determinados conforme as Equações 1, 2 e 3, respectivamente.

$$
\begin{aligned}
& \text { Carvão }(\%)=\left(\frac{m_{\text {carvão }}}{m_{\text {briquete }}}\right) * 100 \\
& \text { Liquido }(\%)=\left(\frac{m_{\text {líquido }}}{m_{\text {briquete }}}\right) * 100 \\
& \text { Gases }(\%)=\left(\frac{m_{\text {briquete }}-\left(m_{\text {liquido }}+m_{\text {carvão }}\right)}{m_{\text {briquete }}}\right) * 100
\end{aligned}
$$

\subsection{Caracterização dos produtos da pirólise}

Caracterização do bio-óleo: Foi realizada a quantificação entre as fases orgânica e aquosa em funil de separação deixando em repouso por 30 minutos. Após a completa decantação fez-se a retirada das fases separadamente. O teste de solubilidade foi realizado com etanol, acetona, éter de petróleo, hexano e cicloexano como solventes. A massa específica do bio-óleo foi calculada utilizando-se picnômetro calibrado de $50 \mathrm{~mL}$. O potencial hidrogeniônico foi determinado utilizando pHgâmetro digital (Policontrol, modelo $\mathrm{pH}$ 250). Para determinar a viscosidade do bio-óleo foi utilizado viscosímetro copo ford (Quimis, modelo Q-280).

Caracterização do carvão: Foram determinadas as massas específicas aparente a partir da massa de carvão que ocupou o espaço até a superfície de uma proveta de $250 \mathrm{~mL}$. O índice de iodo foi determinado conforme descrito na NBR 3410. O teor de cinzas do carvão foi realizado em duplicatas a partir da norma ASTM D-3174 (UNICAMP, 2005) utilizando um 
grama de amostra disposta em cadinho de porcelana levado ao forno mufla a $750^{\circ} \mathrm{C}$ por 6 horas, após foram mantidas em dessecador e pesadas.

\section{RESULTADOS E DISCUSSÕES}

\subsection{Caracterização da biomassa}

Após o processo de secagem o bagaço de malte apresentou um teor de 4,1\% de umidade. De acordo com Asadullah et al. (2007), a umidade da biomassa deve ser pequena para minimizar o conteúdo de água presente no bio-óleo. O percentual calculado de voláteis e carbono fixo para o bagaço de malte foi em média $80,4 \%$ e $11,5 \%$, respectivamente. Comparando com os resultados de Asadullah et al. (2007) para a pirólise do bagaço cana-deaçúcar, obteve rendimento de $75,1 \%$ e $24,9 \%$ de voláteis e carvão, respectivamente. Dessa forma, é esperado que o bagaço de malte apresentasse maiores rendimentos em líquidos condensáveis do que em carvão. $\mathrm{O}$ teor de cinzas do bagaço de malte determinado foi em média de 4\%, valor este superior ao obtido por Asadullah et al. (2007) para o bagaço de canade-açúcar que apresentou teor de cinzas de 1,26\%.

Nos estudos de Asadullah et al. (2007) o bagaço foi triturado para manter o tamanho das partículas entre $0,5 \mathrm{~mm}$ e $1,0 \mathrm{~mm}$ de tamanho. Entretanto, no presente estudo, a análise granulométrica apresentou que $91,71 \%$ da amostra tem tamanho de partículas entre 0,589 e $3,327 \mathrm{~mm}$. A massa específica aparente do bagaço de malte foi $214,31 \mathrm{~kg} / \mathrm{m}^{3}$. Esse valor foi superior ao que foi encontrado para outras biomassas como o bagaço de cana-de-açúcar, que foi de $120 \mathrm{~kg} / \mathrm{m}^{3}$ e da madeira de cedro, de $70 \mathrm{~kg} / \mathrm{m}^{3}$ (ASADULLAH et al., 2007).

Na Figura 1 é apresentado o perfil termogravimétrico do bagaço de malte. Pode-se verificar que a curva termogravimétrica do bagaço de malte apresenta três picos para a variação da perda de massa, que se referem à degradação dos constituintes lignocelulósicos dessa biomassa. A primeira zona de perda de massa entre as temperaturas de 26 e $150^{\circ} \mathrm{C}$ deve-se predominantemente à evaporação da umidade do bagaço de malte, sendo que a perda de massa para essa região foi de 8,42\%. Este percentual foi maior que os 4,1\% obtidos para a análise do teor de umidade. 


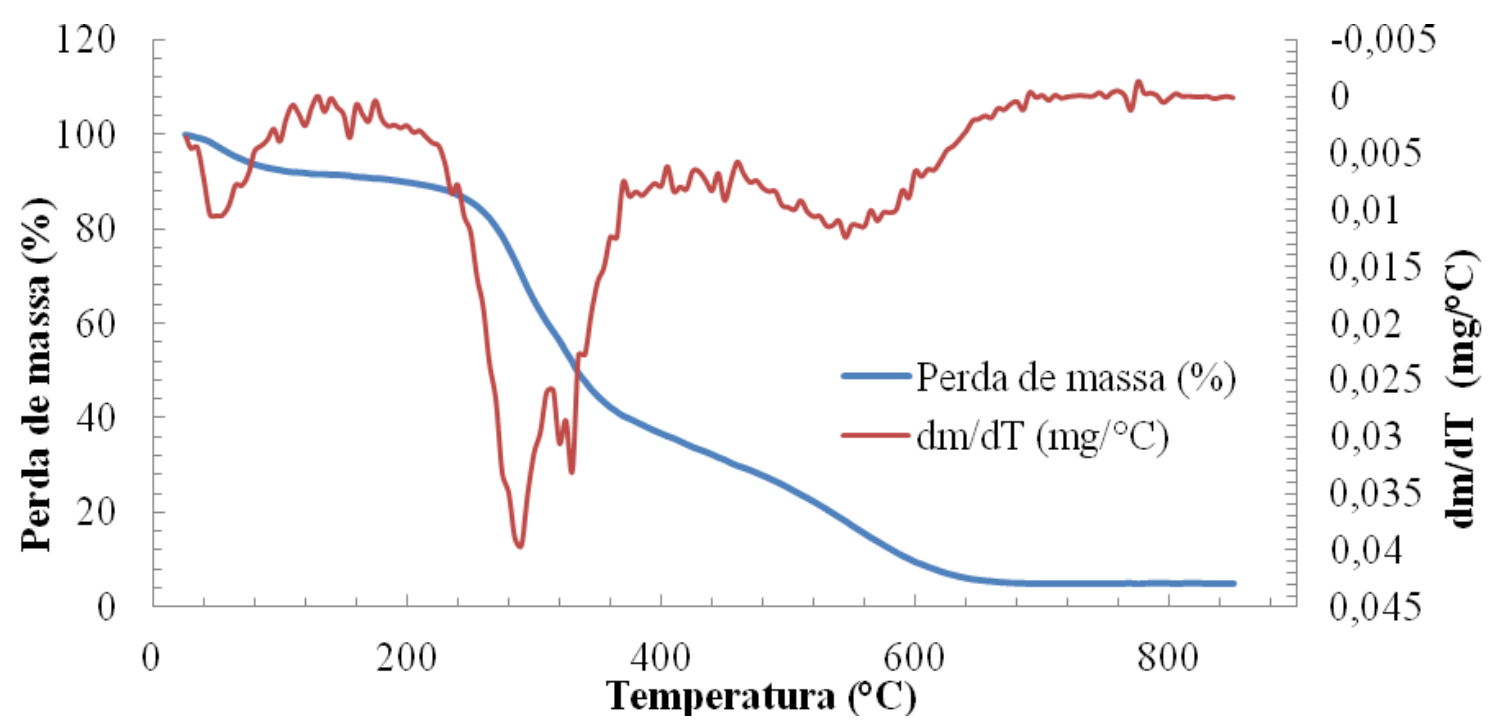

Figura 1 - Perfil termogravimétrico e derivada do perfil termogravimétrico do bagaço de malte.

A segunda zona entre $150^{\circ} \mathrm{C}$ e $400^{\circ} \mathrm{C}$ apresentou maior perda de massa, na ordem de $55 \%$ da massa do bagaço de malte. Conforme Seye, Cortez e Gómez (2003), a celulose e hemicelulose são mais sensíveis à ação térmica e a degradação destes ocorre até a temperatura de $330^{\circ} \mathrm{C}$. Pode-se verificar que ocorreu uma degradação nas temperaturas referentes à presença de celulose e hemicelulose no bagaço de malte. O bagaço de malte, conforme Vaz, Mussatto e Roberto (2011), apresentam aproximadamente $45 \%$ de celulose e hemicelulose.

A terceira zona de perda de massa, entre $400^{\circ} \mathrm{C}$ e $650^{\circ} \mathrm{C}$, que corresponde a degradação de aproximadamente $31 \%$ da massa do bagaço de malte. Conforme citado por Seye, Cortez e Gómez (2003), essa faixa de temperatura pode ser atribuída à degradação da lignina. A lignina é mais resistente à degradação térmica que ocorre em temperaturas superiores a $300^{\circ} \mathrm{C}$. Conforme Vaz, Mussatto e Roberto (2011) a concentração de lignina para o bagaço de malte é de $27,8 \%$. Assim foi observado que o percentual de perda de massa foi semelhante ao percentual de lignina que compõe o bagaço de malte, para a terceira zona de degradação na análise granulométrica.

Acima de $700^{\circ} \mathrm{C}$ não foi observado perda de massa significativa, isso é devido a total devolatilização do material lignocelulósico, restando apenas o carbono fixo e as cinzas, que resultaram em $5 \%$ da massa.

\subsection{Ensaios de pirólise com diferentes taxas de aquecimento}

Os resultados da pirólise do bagaço de malte obtidos a partir dos experimentos realizados com diferentes taxas de aquecimento estão apresentados na Figura 2. Foi observado que o rendimento dos produtos da pirólise do bagaço de malte apresentou pequena variação em relação às taxas de aquecimento estudadas. Os rendimentos obtidos foram de $42,0 \pm 1,1 \%, 30,7 \pm 1,1 \%$ e $27,8 \pm 1,5 \%$ para os líquidos, carvão e gases, respectivamente. Para os ensaios com diferentes temperaturas, foi escolhida a taxa de aquecimento de $20^{\circ} \mathrm{C} / \mathrm{min}$, pois apresentou uma maior facilidade para o controle da taxa de aquecimento. $\mathrm{O}$ rendimento de 
carvão apresentou pequena variação com relação à variação da taxa de aquecimento. Foi observado que o aumento da taxa de aquecimento reduziu a formação do material sólido.

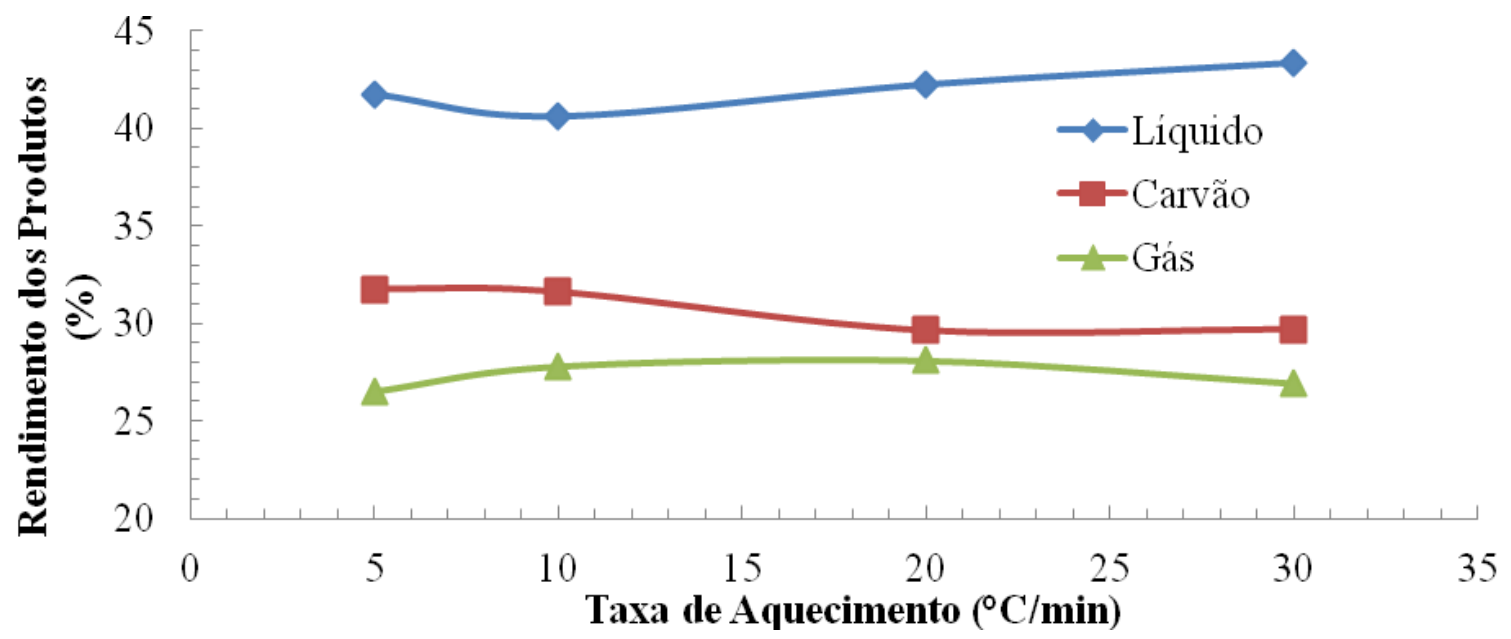

Figura 2 - Distribuição dos produtos da pirólise do bagaço de malte para diferentes taxas de aquecimento.

\subsection{Ensaios de pirólise com diferentes temperaturas}

Os rendimentos dos produtos da pirólise (líquido, carvão e gás) em relação às temperaturas entre $300^{\circ} \mathrm{C}$ e $650^{\circ} \mathrm{C}$ estão representados na Figura 3. Foi observado maior rendimento de carvão que de bio-óleo para a temperatura de $350^{\circ} \mathrm{C}$, sendo que para o carvão foi maior que $43 \%$ e para o bio-óleo menor que $35 \%$ para essa temperatura. A partir da Figura 4, a soma dos produtos líquido e gás para a temperatura de $350^{\circ} \mathrm{C}$ é de aproximadamente $57 \%$. Esse comportamento está de acordo com a análise termogravimétrica do bagaço de malte que apresentou uma degradação de $55 \%$ da massa até a temperatura de $350^{\circ} \mathrm{C}$.

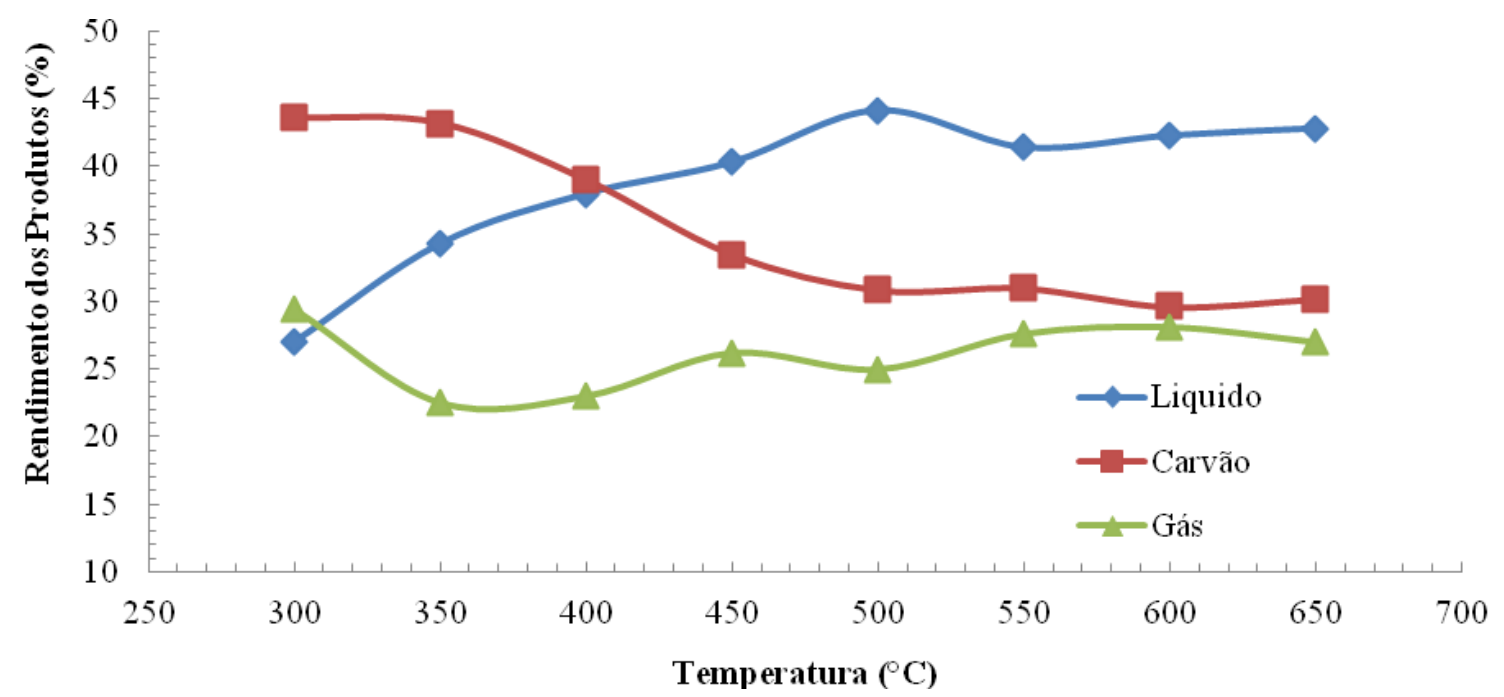

Figura 3 - Rendimento dos produtos da pirólise com a temperatura final do processo. 
Entre as temperaturas de 350 e $500^{\circ} \mathrm{C}$ observou-se uma diminuição no rendimento de carvão. Este comportamento está de acordo com o perfil termogravimétrico, que nessa faixa de temperatura para o bagaço de malte apresentou grande perda de massa, na ordem de $19,5 \%$.

Foi observado que o aumento de temperatura propiciou o aumento no rendimento de líquido concomitante com a diminuição no rendimento de carvão. $\mathrm{O}$ maior rendimento de líquido foi observado para a temperatura de $500^{\circ} \mathrm{C}$ com $44,1 \%$ de líquido e $30,8 \%$ de carvão. Os estudos de Asadullah et al. (2007) para a pirólise do bagaço de cana-de-açúcar apresentaram resultados semelhantes, em que o maior rendimento de líquido foi observado na temperatura de $50{ }^{\circ} \mathrm{C}$, obtendo $66 \%$ de líquido e $24 \%$ de carvão. O rendimento de gases apresentou variação de aproximadamente $7 \%$ entre as temperaturas estudadas. $\mathrm{O}$ maior rendimento verificado foi de $29 \%$ na temperatura de $300^{\circ} \mathrm{C}$, e o menor rendimento foi de $22 \%$ na temperatura de $350^{\circ} \mathrm{C}$.

\subsection{Caracterização dos produtos da pirólise}

A Tabela 1 apresenta a caracterização do bio-óleo da pirólise do bagaço de malte. A fase aquosa apresentou alta fluidez, coloração castanha e odor de fumaça. A fase orgânica possui características semelhantes de um óleo pesado com alta viscosidade de coloração preta e odor de fumaça. O bio-óleo foi quantificado em relação às fases e foi observado que a fase aquosa foi predominante e correspondeu $60,45 \%$ da mistura, já a fase orgânica representou 39,55\%.

Tabela 1 - Caracterizações do bio-óleo do bagaço de malte.

\begin{tabular}{|c|c|c|c|}
\hline \multicolumn{2}{|c|}{ Propriedade } & Fase aquosa & Fase orgânica \\
\hline \multicolumn{2}{|c|}{ Aparência } & $\begin{array}{l}\text { Coloração marrom } \\
\text { castanho }\end{array}$ & $\begin{array}{l}\text { Alta viscosidade e } \\
\text { coloração preta }\end{array}$ \\
\hline \multicolumn{2}{|c|}{ Fração mássica do bio-óleo (\%) } & 60,45 & 39,55 \\
\hline \multicolumn{2}{|c|}{ Massa específica $\left(\mathrm{kg} / \mathrm{m}^{3}\right)$} & 1039,97 & 962,41 \\
\hline \multicolumn{2}{|c|}{ Viscosidade (centstoke) } & 0,98 & 206,17 \\
\hline \multicolumn{2}{|c|}{$\mathrm{pH}$} & 5,80 & 6,10 \\
\hline \multirow{5}{*}{ Solubilidade } & Acetona & Solúvel & Solúvel \\
\hline & Etanol & Solúvel & Solúvel \\
\hline & Cicloexano & Insolúvel & Solúvel \\
\hline & Éter de petróleo & Insolúvel & Solúvel \\
\hline & Hexano & Insolúvel & Solúvel \\
\hline
\end{tabular}

De acordo com a Tabela 1 a massa específica obtida foi de 1039,97 kg/m³ e 962,41 $\mathrm{kg} / \mathrm{m}^{3}$, para a fase aquosa e orgânica, respectivamente. A massa específica de um combustível de petróleo, conforme citado por Asadullah et al. (2007), é de $850 \mathrm{~kg} / \mathrm{m}^{3}$. A densidade elevada dos bio-óleos de pirólise ocorre pelo alto teor de oxigênio que constitui as moléculas desse produto, ao contrário dos combustíveis derivados do petróleo que tem maior composição de aromáticos policíclicos (ASADULLAH et al., 2007).

A viscosidade cinemática para a fase orgânica do bio-óleo foi de 206,17 centistokes para a temperatura de $25^{\circ} \mathrm{C}$. Este valor está de acordo com os parâmetros citados por Mohan, Pittman e Steele (2006) em que o bio-óleo apresenta, em geral, viscosidade entre 25 e 1000 centstokes na temperatura de $40^{\circ} \mathrm{C}$. A fase aquosa do bio-óleo apresentou viscosidade cinemática de 0,98 centstokes na temperatura de $25^{\circ} \mathrm{C}$. 
Conforme a Tabela 1, a fase aquosa do bio-óleo apresentou $\mathrm{pH}$ 5,8 sendo por isso também conhecida de fase aquosa ácida por apresentar $\mathrm{pH}$ ácido. A fase orgânica apresentou pH de 6,1. Segundo Asadullah et al.(2007) o pH encontrado para os produtos líquidos da pirólise do bagaço de cana-de-açúcar foi entre 3,5 e 4,5.

Para o teste de solubilidade do bio-óleo do bagaço de malte, a fase aquosa apresentou solubilidade apenas nos solventes polares (acetona e etanol) sendo, portanto insolúvel nos solventes orgânicos apolares estudados. Por outro lado a fase orgânica apresentou solubilidade em todos os solventes estudados (acetona, etanol, cicloexano, éter de petróleo e hexano).

A caracterização do carvão do bagaço de malte apresentou um índice de iodo 237,21 miligramas de iodo por grama de carvão. Isso é um indicativo de que o carvão pirolisado do bagaço de malte apresenta uma estrutura porosa pouco desenvolvida em virtude do baixo índice de iodo. Para a utilização como adsorvente faz-se necessário um processo de ativação, que poderá desenvolver a porosidade aumentando a área superficial deste carvão. A massa específica do carvão pirolisado do bagaço de malte foi de $185,24 \mathrm{~kg} / \mathrm{m}^{3}$ valor este abaixo do obtido para o bagaço de malte seco que foi de $214,30 \mathrm{~kg} / \mathrm{m}^{3}$. O teor de cinzas foi de $10,07 \%$ para o carvão pirolisado. Valor este maior que o teor de cinzas do bagaço de malte que apresentou 4,0\%. Essa característica foi esperada sendo que o processo de pirólise degradou os constituintes do bagaço de malte concentrando o teor de cinzas no carvão.

\section{CONCLUSÕES}

A análise termogravimétrica do bagaço de malte revelou três faixas de perda de massa referentes à devolatilização dos constituintes da biomassa.

Os ensaios de pirólise com diferentes taxas de aquecimento apresentaram pequena variação no rendimento dos produtos. Por outro lado, os ensaios com diferentes temperaturas de pirólise, entre 300 e $650^{\circ} \mathrm{C}$, apresentaram grandes variações, sendo que a $500^{\circ} \mathrm{C}$ apresentou maior rendimento de bio-óleo $(42,0 \pm 1,1 \%)$ e $30,7 \pm 1,1 \%$ e $27,8 \pm 1,5 \%$ para o carvão e gases, respectivamente. O bio-óleo da pirólise do bagaço de malte apresentou uma mistura heterogênea (fase aquosa e orgânica) com predominância da fase aquosa. A fase aquosa apresentou massa específica de $1039,97 \mathrm{~kg} / \mathrm{m}^{3}$ e coloração marrom castanho com odor de fumaça, também apresentou solubilidade nos solventes polares estudados. A fase orgânica apresentou alta viscosidade (206,17 centstoke) com massa específica de $962,41 \mathrm{~kg} / \mathrm{m}^{3}$, coloração preta e odor de fumaça, essa fase apresentou solubilidade nos solventes polares e apolares estudados. O carvão pirolisado apresentou baixa adsorção de iodo, indicando assim que o carvão apresenta estrutura porosa pouco desenvolvida. Porém este carvão pode ser utilizado como matéria prima para a produção de carvão ativado.

Assim, o bagaço de malte apresentou-se como uma fonte promissora para aplicação em processos de pirólise para obtenção de líquidos condensáveis (bio-óleo) e carvão.

\section{REFERÊNCIAS}

ASADULlAH, M; RAHMAN, M. A; ALI, M. M; RAHMAN, M. S; MOTIN, M. A; SULTAN, M. B; ALAM, M. R. Production of bio-oil from fixed bed pyrolisis of bagasse. Fuel, v. 86, p. $2514-2520,2007$ 
MOHAN, D; PITTMAN, C. U; STEELE, P.H. Pyrolysys of Wood/Biomass for Bio-oil: A Critical Review. Energy \& Fuels, v. 20, p. 848 - 889, 2006.

SÁNCHEZ, C. G; CAMPO, E. R. B. Tecnologia da gaseificação. Faculdade de Engenharia Mecânica, Departamento de Engenharia Térmica e de Fluidos, Universidade Estadual de Campinas, Campinas, SP, p. 5-2, 5-17, 2003.

SEYE, O; CORTEZ, L. A; GÓMEZ, E. O. Estudo cinético da biomassa a partir de resultados termogravimétricos. Enc. Energ. Meio Rural, 2003.

UNICAMP. Tecnologia da gaseificação. Departamento de Engenharia Térmica e de Fluidos, Faculdade de Engenharia Mecânica. Universidade Estadual de Campinas, cap. 2, 2005.

VAZ, A. C. S; MUSSATTO, S. I; ROBERTO, I. C. Avaliação da composição química do hidrolisado hemicelulósico do bagaço de malte visando sua utilização em processos fermentativos. FAPESP, 2011.

OKUTUCU, C.; DUMAN, G.; UCAR, S.; YASA, I.; YANIK, J., Production of fungicidal oil and activated carbono from pistachio shell. J. Anal. Appl. Pyrolysis , 91, p. 140-146, 2011.

JOARDDER, M. U. H.; UDDIN, M. S.; ISLAM, M. N., The utilization of waste date seed as bio-oil na activated carbono by pyrolysis process, Adv. Mechanic. Eng., p. 1-6, 2012.

AI, N., ZENG, G. ZHOU, H. HE, Y., Co-production of Activated Carbon and bio-oil from agricultural residues by molten salt pyrolysis, BioResource, v. 8(2), p. 1551-1562, 2013. 